\section{The effects of preexposure to a learning apparatus}

\author{
MICHAEL GRANT and DENNIS YOUNG \\ The University of Bridgeport, Bridgeport, Connecticut 06602
}

ICR mice were given exposure to a one-way shuttle apparatus until locomotor activity had been habituated. When compared with nonexposed animals, the exposed animals displayed superior shuttle avoidance learning. Animals exposed to both the apparatus and the CS did not differ from the nonexposed group. It was concluded that preexposure to the learning apparatus facilitated acquisition, while preexposure to the apparatus in the presence of the CS did not. The relationship between this effect and habituation was considered.

Several investigators have attempted to determine if there is an attenuation of conditioning when an animal is habituated to a conditional stimulus prior to the onset of conditioning trials (Lubow, 1965; Suboski, DiLollo, \& Gormezano, 1964; Carlton \& Vogel, 1967). Lubow (1965) reported a deficit in the strength of a conditioned leg flexion response in sheep, when animals had been preexposed to the CS. Carlton and Vogel reported a similar effect in the conditioning of a one-trial conditioned emotional response to a tone, when the animals were given 10 presentations of the tone prior to the tone-shock pairing. The authors concluded that there was a loss in the functional impact of a stimulus to which animals had been habituated, and that this made it impossible to obtain one-trial conditioning to the stimulus. Suboski, DiLollo, and Gormezano (1964) did not find the deficits reported above in conditioning a nictitating membrane response in rabbits.

In the present study, animals were habituated to the environmental stimuli present in a one-way shuttlebox, with the exception of a tone to be used as the CS. It was hypothesized that this should intensify the impact of the CS and, in this manner, facilitate conditioning. Grant (1969) reported that locomotor activity in a novel environment declines over the course of an exposure session as a function of habituation to the environmental stimuli. The effects on subsequent conditioning of exposing animals to the learning apparatus in the presence and absence of the CS were compared with a nonexposed control group.

\section{METHOD}

\section{Subjects and Apparatus}

The Ss were 36 ICR mice that were about 45 days old at the start of the experiment. A Lehigh Valley mouse shuttlebox was programmed to deliver a $1,000-\mathrm{Hz}$ tone for $5 \mathrm{sec}$, followed by a pairing of tone and shock $(.8 \mathrm{~mA})$ cross-hatched into 1-in. squares with photocells, so that locomotor activity and shuttling latency could be recorded.

\section{Procedure}

Animals were divided randomly into an exposed (E), exposed with tone (E-T), or nonexposed (N-E) group for $15 \mathrm{~min}$ and allowed to explore both sides while locomotor activity was being monitored. Animals were reintroduced to the environment until they had met the E's operational definition of habituation. Habituation was defined as a lower amount of day, plus a period of three consecutive exposures in which the variance of until the animal escaped. The box was photocell activity than on the first activity did not deviate by more than $15 \%$ in either direction. Individual animals took between 7 and 19 exposure sessions to reach this criterion. After reaching the habituation criterion, animals were immediately started on a series of one-way shuttle avoidance trials, which continued until an animal met a criterion of four consecutive avoidances. E-T animals were treated in the same manner as $E$ animals, except that during exposure a tone was presented on a VI 1-min schedule. The N-E group was removed from their home cages and exposed to a carrying cage for an equivalent amount of time as the other groups. The N-E animals were given a 5 -min preexposure session to the apparatus before the start of the learning trials.

\section{RESULTS}

The dependent variable for all groups was the number of trials to reach a criterion of four consecutive a voidances. Figure 1 presents the median number of trials to criterion for each group. After a Kruskal-Wallis $H$ test had revealed significant ( $\mathrm{p}<.05 ; \mathrm{H}=9.64$ ) differences among the three groups, Mann-Whitney U comparisons were performed between the $E$ and $N-E$ and the N-E and $E-T$ groups. The $\mathrm{E}$ group was found to have taken significantly fewer trials $(p<.05)$ to reach criterion than the N-E group. There was no reliable

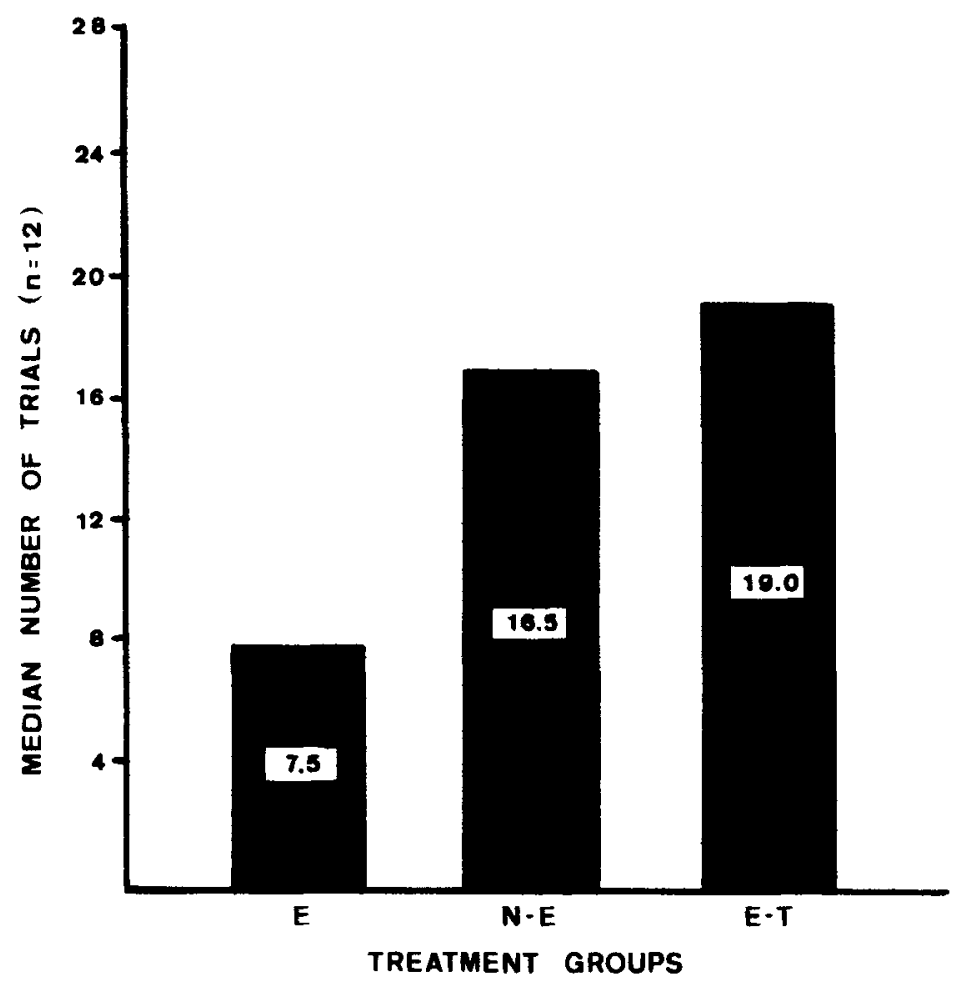

Fig. 1. Median trials to criterion as a function of exposure to apparatus. 
difference between $\mathrm{N}-\mathrm{E}$ and the $\mathrm{E}-\mathrm{T}$ groups.

A Spearman rank-order correlation coefficient was computed for the $\mathrm{E}$ and the E-T groups, comparing number of sessions to reach the habituation criterion with number of trials to reach the learning criterion, and the low correlation $(r=+.21)$ was taken as an indication that habituation per se was the relevant variable, rather than the amount of exposure time.

\section{DISCUSSION}

The results indicate that there is a significant effect of preexposing an animal to an apparatus, and that this effect can subsequently alter the course of learning in this apparatus. The present study is in agreement with the findings of Lubow (1965) and Carlton and Vogel (1967). These results extend the influences of prior habituation from a classical to an instrumental learning situation. In addition, they demonstrate a facilitatory effect of habituation on instrumental conditioning. The poorer performance of the E-T group as compared to the $E$ group can be taken to indicate that exposure to the CS exerts more of a negative influence on learning than exposure to the learning environment exerts a positive influence. Traditionally, animals have been briefly exposed to the learning apparatus to allow them some time to adjust to their surroundings. The present study demonstrates that the effects of being exposed to a novel environment can extend to as many as 16 exposure sessions lasting $15 \mathrm{~min}$ each.

Carlton (1965) has suggested that there is a relationship between cholinergic functioning in the central nervous system and the process of habituation. It would be interesting to observe the effects of manipulating cholinergic functioning during the preexposure sessions. There is evidence to suggest that the impairment of cholinergic functioning can disrupt the acquisition of a conditioned avoidance response (Herz, 1960). A possible explanation of this effect could be the inability of the animal to habituate, or screen out, the irrelevant cues in the learning environment, making it more difficult to attend to the one relevant cue, the CS.

\section{REFERENCES}

CARLTON, P. L. The hippocampus, brain-acetylcholine and habituation. Paper read at the Symposium on Brain. Biochemistry and Behavior, AAAS meetings, 1965.

CARLTON, P. L.. \& VOGEL, J. Habituation and conditioning. Journal of Comparative \& Physiological Psychology, $1967,63,348-351$.

GRANT, M. Cholinergic influence on activity in a novel environment. Paper read at the Eastern Psychological Association meeting, 1969.

HERZ, A. Drugs and the CAR. International R eview of Neurobiology, 1960, 2 , 229-277.

LUBOW, R. E. Latent inhibition: The effect of frequency of nonreinforced preexposure to the conditional stimulus. Joumal of Comparative \& Physiological Psychology, 1965, 60, 454-457.

SUBOSKI, M. D., DiLOLLO, V., \& GORMEZANO, I. Effects of preacquisition exposure of the $\mathrm{CS}$ and UCS on classical conditioning of the nictitating membrane response of the albino rabbit. Psychological Reports, 1964, 15, 571-576. 